http://www.moderntechno.de/index.php/meit/article/view/meit07-02-052 DOI: 10.30890/2567-5273.2019-07-02-052

\title{
УДК. 7.012.001.891
}

\section{MODERN COLORING TRENDS IN THE INDUSTRIAL CARPET DESIGN OF THE REPUBLIK OF MOLDOVA СОВРЕМЕННЫЕ ТЕНДЕНЦИИ КОЛОРИРОВАНИЯ В ДИЗАЙНЕ ПРОМЫШЛЕННЫХ КОВРОВ РЕСПУБЛИКИ МОЛДОВА}

Babina Yu. / Бабина Юлиана

State Pedagogical University. I. Creanga, Chisinau, Republic of Moldova Государственный педагогический университет им. И. Крянгэ, Кишинев, Республика Молдова

Аннотация. В данной статье подробнее изучаются основные колориты современных напольных покрытий и ковров, разработанных в течение десятков лет профессиональными художниками и колористами в ходе развития коврового производства на текстильном комбинате $A O$ Флоаре-Карпет в Кишиневе. Автор подводит четкую классификачию ковровых изделий по существуюшим коллекциям и краткий перечень излюбленных покупателями образиов. Даны основные характеристики самых популярных ковров предприятия и советы по их применению (выбору изделия) в ансамбле украшения пространства современных интерьеров. При подведении итогов исследования предложень рекомендации.

Ключевые слова: ковры, колорит, современность, дизайн, традиции, узор/орнамент, интерьер, индустриальная система, АО Floare-Carpet, Молдова.

\section{Введение}

В наше время важную роль при выборе коврового полотна для уюта и обустройства дома, являющегося своего рода финальным аккордом в дизайнерском решении, играет подходящий колорит текстильного изделия. Известно, что стиль винтаж подходит для любителей классики, авангард и модерн - для современных ценителей искусства, прованс - для мечтающих и ценящих романтику Франции.

В XX-XXI вв. изучением особенностей традиционной колористики, содержания системы орнаментальной иконографии и художественноморфологической структуры традиционных ковров в пруто-днестровском междуречье, занимались следующие ученые, искусствоведы и этнографы, $B$. Тесленко, С. Шарануиуа, Д. Гоберман, Д. Комиа, Г. Мардарь, Е. Постолаки, В. Зеленчук, Дю. Стойка, С. Чуботару, 3. Шофрански, Т. Ставилэ, В. Бузилэ, А. Симак, Л. Моисей и др. Но исследованию современных ковров в индустриальной системе Mолдовы уделяется недостаточно внимания, что послужило главной причиной возросшего интереса, изучения данного аспекта проблем ковроделия в республике [1-2]. Весь спектр ковровых изделий на любой вкус покупателя представляет Кишиневская фабрика AO Флоаре-Kapnem (1978 г.), Рис. 2. За 40-летний период творческой деятельности художественной мастерской и сформированной в ней школы, талантливые художники постарались воссоздать на ковровых полотнах древние орнаменты традиционных тканей, рожденных ранее в Европе (а именно на территории Бессарабии), Азии и на Ближнем Востоке [2].

Цель статьи - ознакомить зарубежных художников, дизайнеров, 
колористов, ковроделов, искусствоведов, культурологов, студентов и педагогов с богатым ковровым ассортиментом (и цзветовой гаммой) в индустриальной системе Республики Молдова, основываясь на закреплении полезного материала, на разработках профессиональных художников в области проектирования и колорирования ковров в современном контексте.

\section{Результаты исследования их обсуждение}

Проанализируем основные и наиболее интересные на взгляд автора колоритыл. Расиветки 1659 и 61569 были созданы специально для европейской коллекции ковров, в основе которых лежит кремовый цзвет. Золотой и коричневый - частые спутники кремового, и в этих расцветках они также присутствуют. Обычно яркий бордовый цзвет акцентирует внимание зрителя на важных деталях узора, более мягкий розовый - облегчает излишнюю торжественность. Пастельная цветовая гамма колорита 1659 очень популярна у потребителей, в связи с возросшим интересом общества к светлым интерьерам. Кремовый тон смягчает интерьер и добавляет пространству объема. Колорит «Кремовый бордо» используют для окрашивания ковров светлых тонов. Доля бордо - не велика, но им окрашены наиболее важные элементы коврового pисунка. Роскошный и эстетически привлекательный ковер L'amur №472 в данной цветовой гамме (61659) также выглядит очень достойно [4].

Колориты с фоновым цзветом зеленого спектра (например, 60526 полынь, бордовый, золотой, оливковый, кремовый, розовый) ассоциируются с природной гармонией, и моментально успокаивают. Оттенок «полынь» поддерживает более темный оливковый из той же цзветовой гаммы, а детали проработаны бордовым и розовым. Ковры зеленых оттенков вписываются в теплые пастельные интерьеры, сочетаются с коричневыми, светло-серыми или жёлтыми цветами, использованными в декоре помещения. Покрытие расцветки 60526 отлично подойдет в качестве фона в спальной комнате или в гостиной. Облегченный дизайн этого европейского ковра делает возможным его использование в интерьерах разной направленности: классика, современные направления, английский стиль и минимализм. Благодаря неброскому узору ковер Fragrance 477 (по дизайну Ермилиной Татьянь) покупатели часто предпочитают использовать как фоновое покрытие [1]. Безусловно, с расиветкой 60526 более всего ассоциируется нежный и очень популярный ковер European (дизайн был разработан в 2014 г. ведущим художником мастерской - Котельниковой Светланой Федоровной).

Классическая коллекция (Classic) состоит из персидских ковров, имеющих многовековую традицию, популярных во все времена: 1.Forestry №47; 2.Spoleto №72; 3.Bagdad №65; 4.Bouquet №101; 5.Reghistan №104; 6.Agat №102; 7.Rose №113; 8.Teatral №115; 9.Bisser №125; 10.Mashad №139; 11.Birma №140; 12.Abadan №178; 13.Medjnun №286; 14.Isfahan №207; 15.Edem №249; 16.Summer №107 и др. (См. Рис. 1.) Огромный вклад в разработку множества восточных ковров внесла в свое время профессиональная художница Елена Тычук.

Kовры восточной стилистики по традициии часто окрашивают в оливковый цвет (колорит 5542), давно полюбившийся ковроделам. Наши 
специалисты по колористике подобрали колорит, где оливковый оттенок соседствует со светлым кремом, а небольшие элементы узора окрашены в темно-коричневый и золотой тона. Позднее стали применять этот колорит и при окрашивании орнаментов, решенных в европейском стиле. Существует вариация этого колорита «темная бронза», где оливковый цвет заменен на более темный зеленый оттенок. Ковер Summer 107 в колорите 5542 с цветочным орнаментом ассоциируется и с гостиной комнатой и классическим рабочим кабинетом, обставленными массивной дубовой мебелью с покрытиями в виде зеленого сукна [3-4].

Колорит 16591 (тонированный кремовый, терракотовый, темнокоричневый, золотой, темно-золотой) - один из немногих немарких вариантов в светлой расцветке. Она была создана для серии Antique, изначально для ее создания был изменен колорит 1659. Вместо кремового сюда добавлен тонированный кремовый, а бордовый заменен на терракотовый. Эти изменения создают более сглаженный вариант кремового бордо с «эффектом старения», чтобы узор не казался излишне вычурным [4]. Уникальная коллекция Antique, в стиле антикварных ковров, представлена серией: 1.Laura №260; 2.Rassam №261; 3.Ritm №262; 4.Florena №266; 5.Stella №269; 6.Saleh №270; 7.Nocturne №272; 8.Ararat №435; 9.Darius №436; 10.Safid №437;11.Ahmad №439; 12.Akbar №441; 13.Cinara №442; 14.Village №467; 15.Nizami №267; 16. Vega №271; 17.Safir №471 (Рис. 1).

Арабески - основной узор персидских ковров (например, Arabes) - в средние века европейцы иначе называли «боязнью пустоты». Поверхность данного ковра полностью усыпана крупным цветочным узором (Рис. 1). Как и любой восточный ковер, популярный в мире Isfahan и родственный ему Nain (без медальона в центре) при точном подборе расцветки сочетается со всевозможными вариантами традиционных стилевых направлений декора от неувядающей классики и английской строгости до переживающего второе рождение деревенского Прованса. Причем это покрытие стоит рассматривать как центральный элемент дизайна, вокруг которого выстраивается окружающий интерьер. Восточный ковер, покрытый изящным цветочным узором, подойдет в оформленную в Классическом стиле гостиную/спальню [4]. Колорит 1149 - довольно универсален, поскольку входящие в него тона гармонично сочетаются друг с другом. Kовры со светло-бежевой основой найдут место почти в любом интерьере, поскольку этот тон очень близок к натуральному цвету некрашеной шерсти. Изящный и вместе с тем легкий узор, простой для восприятия рисунок ковров Magic, Edem, Arabes (aвтор - Елена Тычук) стал для дизайнеров своеобразной находкой: этот восточный орнамент великолепно смотрится как в формах квадрата или прямоугольника, так и в формах овала или круга (Рис. 1). Главная особенность этих персидских ковров они идеально подходят к любым интерьерам и всегда пользуются большим спросом [1].

Рассмотрим ковер Safari №13 (Рис. 1, первый в нижней цепочке моделей), в расцветках 1149 и 1659 (в таком же духе «египетская» Гиза в колорите 1149). Восточные узоры всегда были актуальны в традиционных интерьерах в духе 
классики или прованса, а популярные ныне африканские орнаменты, особенности чужеземной флоры и фауны дальних континентов свободно уживаются с современными веяниями дизайнерской мысли [4].
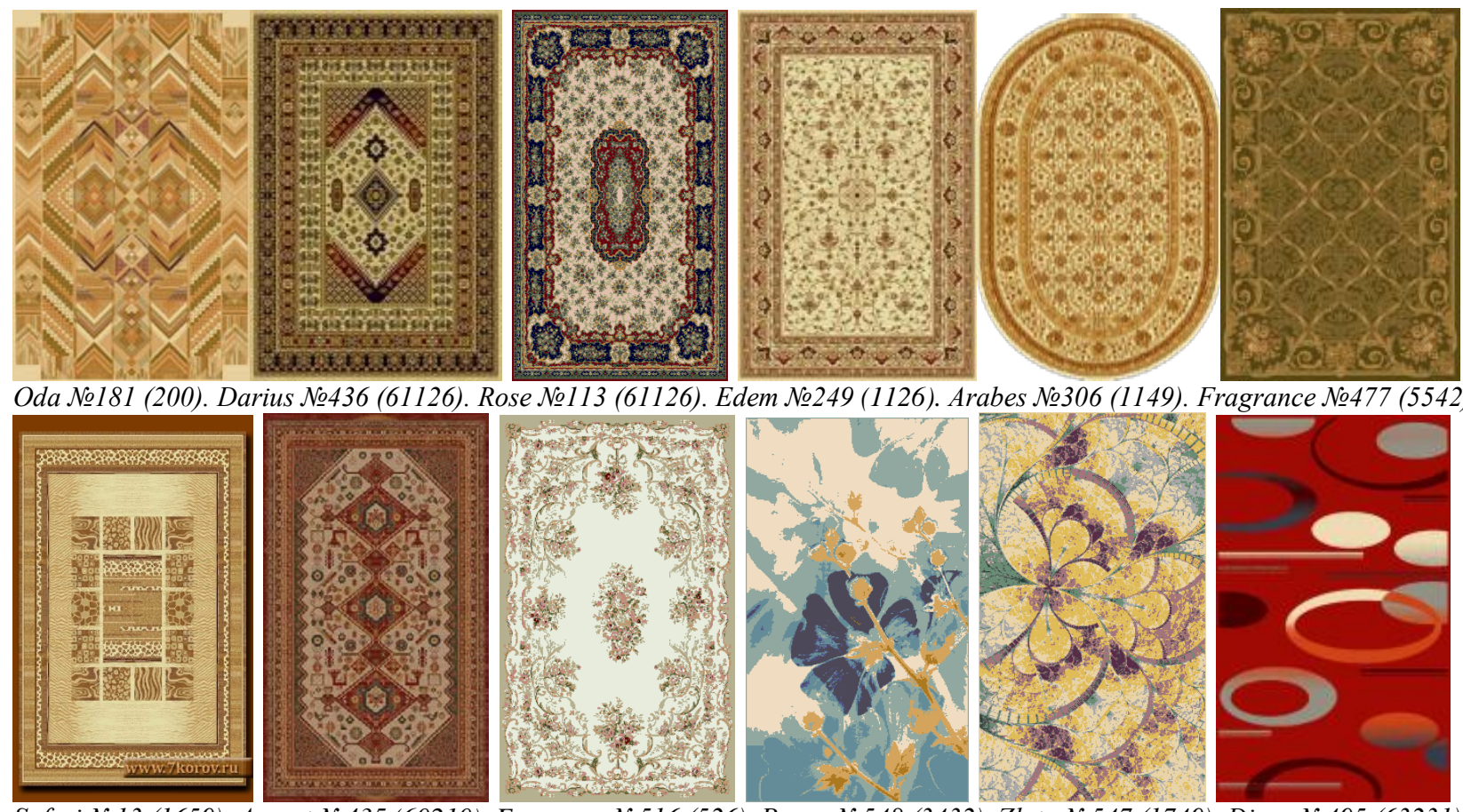

\section{Рис.1.Модели ковров и расцветок из коллекций АО Флоаре-Карпет (Фото: сайт предприятия)}

Огромный выбор ковров из антикварной коллекции (например, ковры Ararat в расиветке 60210, Darius в колорите 60311 и Safid в геометрическом стиле и «сладком» карамельном цвете 60312), обогащенных старинными мотивами и в приглушенных тонах, рассчитан на ценителей традиционного искусства и покупателей с самым изысканным вкусом.

Разнообразие направлений в современном дизайне стилистик от минимализма до эклектики отображено в следующем списке ковров из коллекичии Модерн: 1.Safari №13; 2.Miracle №114; 3.Jacquard №122; 4.Oda №181; 5.Adagio №337; 6. Damasc №443; 7.Diuna №447; 8.Mirror №456; 9.Decor №494; 10.Tanzania №529; 11.Eiforia №503; 12.Salamandra №502; 13.Disco №495; 14.Fenix №501; 15.Lavanda №234; 16.Fregat №250; 17.Shimmer №291; 18.Ghize №9; 19.Capella №457; 20.Popart №499; 21.X-Files №524; 22.Nord №520; 23.Pansy №548; 24.Zlata №547; 25.Rain №534; 26.Totem №575; 27.Indigo №578; 28.Alilat №572; 29.Estella №526 и др. (см. Рис. 1.) Воплощением стилистики Модерна занимались следующие художники-дизайнеры: Путреша Наталья (ответственный колорист), Логвиненко Наталья, Тычук Елена, Бабина Юлиана, Бурлака Ирина, Стоян Наталья, Котельникова Светлана, Булат Наталья, Коновалова Ольга и др. (Рис. 2).

Довольно универсальная расцветка 4544 однако редко используется при окраске ковров, но подходит в пространства, решенные в различных тонах. В светлом варианте такой ковер становится гармоничной частью пространства, a 

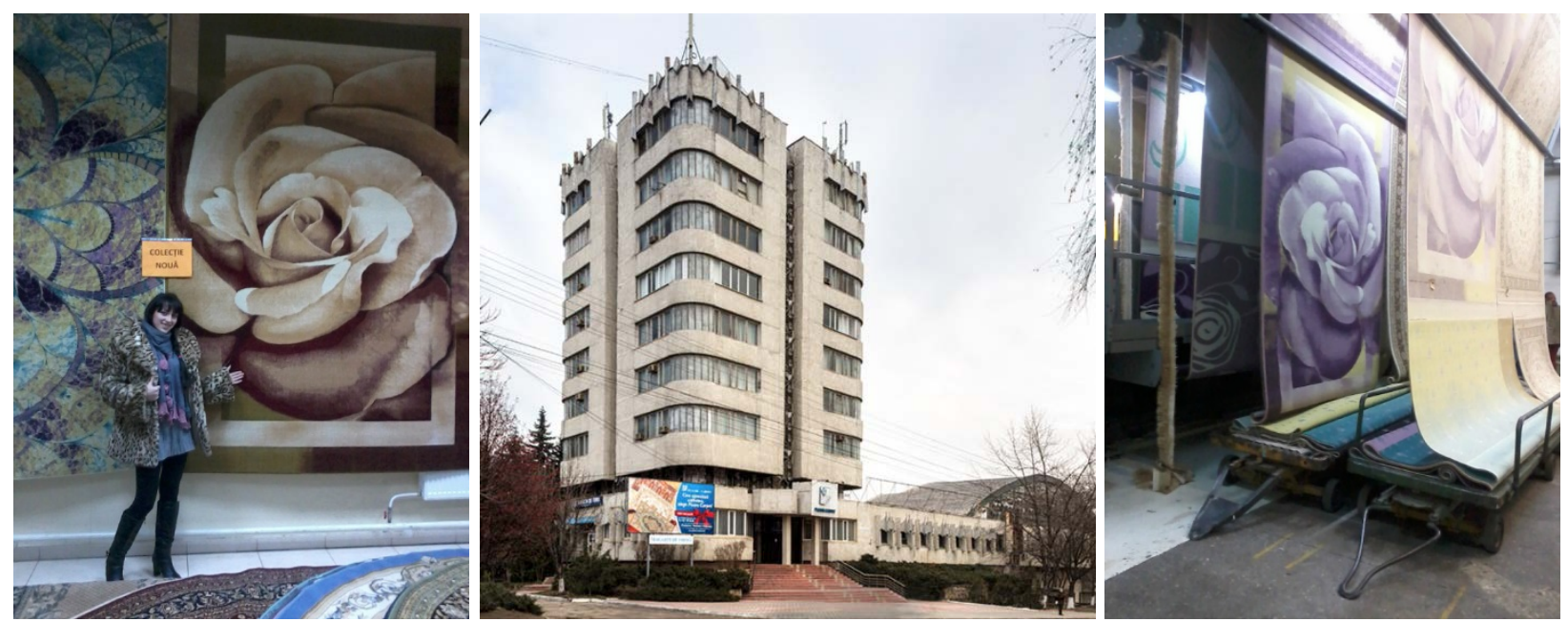

Ю. Бабина - дизайн ковров Модерн. Фабрика АО Флоаре-Карпет. Ткаикий Цех (Станок СRХ)

Рис. 2. Фото из личного архива автора, 2014-2018 (Коллекция Модерн, АО Флоаре-Карпет)

в темном - контрастным акцентом (ковер Nuance 301, Aquamarin 189). В рисунках: Safari 13, Savanna 216, Cashtan 196, Damasc 443, Tanzania 529, Capella 457, Décor 494, Shimmer 291, Lavanda 234, художники искали компромиссное сочетание классических приемов с инновационным подходом к дизайну (Рис. 1-3). Одновременно сохранив растительные элементы, свойственные узорам Европы и Востока, с примесью зооморфных орнаментов и геометризованных объектов [2; 4]. В колорите 3658 специалисты использовали контрастные цвета, где яркий бордовый оттенен золотым и коричневым. Подобная расиветка применяется в классических европейских и восточных покрытиях, а ее главная особенность - долговечность (Sensi 256, Jadi 338, Nain 305, Mashad 139 и др.) [4].

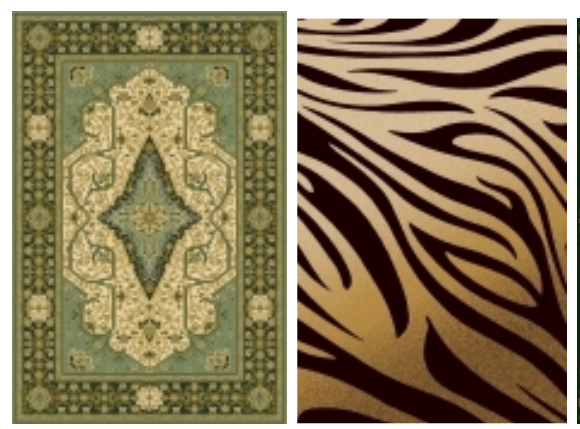

Gherati No566 (63417). Tanzania No529 (61149). Bur

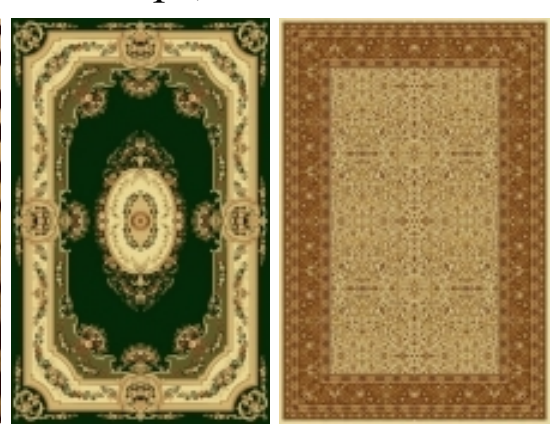

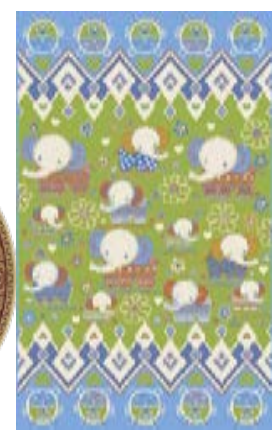

Рис.3.Модели ковров и расцветок из коллекций АО Флоаре-Карпет (Фото: сайт предприятия)

Сегодня абстракиия стала одним из самых интересных узоров для всех желающих купить современный ковер. Такие рисунки пришли в ковроткачество из таких направлений как авангард и модерн с начала XX-го века. Современные напольные ковры Флоаре-Kapnem (Modern, Etude, Folk, Fusion, Graphic, Kids) авангардного направления, стиля поn-арт и хай-тек это настоящий геометрический танец на ворсе, разнообразие графических приемов, символики и орнаментащии, и самые смелые дизайнерские решения (Рис. 2-3). Яркие цвета (желтый, оранжевый, коралловый, красный, 
фиолетовый, бирюза, сиреневый, розовый), неожиданные композиционные компоновки (без стандартных частей/элементов - каймы, медальона), геометрические фигуры (овал/круг/квадрат/мини-ковры) - все это появляется в абстрактных коврах предприятия, как вихрь, ворвавшийся в живопись с появлением авангардистов. «Авангардные контрасты» - верные спутники абстрактного узора. А в сочетании с нетрадиционными формами (квадрат, овал, круг, маленькие ковры-сувениры) подобные ковры не только удачно зонируют и украшают пространство, создавая необходимый фон помещению, но и отвечают требованиям современной модыl. Рассмотрим и главные молдавские сувениры, давно изготавливаемые предприятием с учетом этноценностных ориентаций, национальных особенностей и традиционного колорирования (Рис. 4).
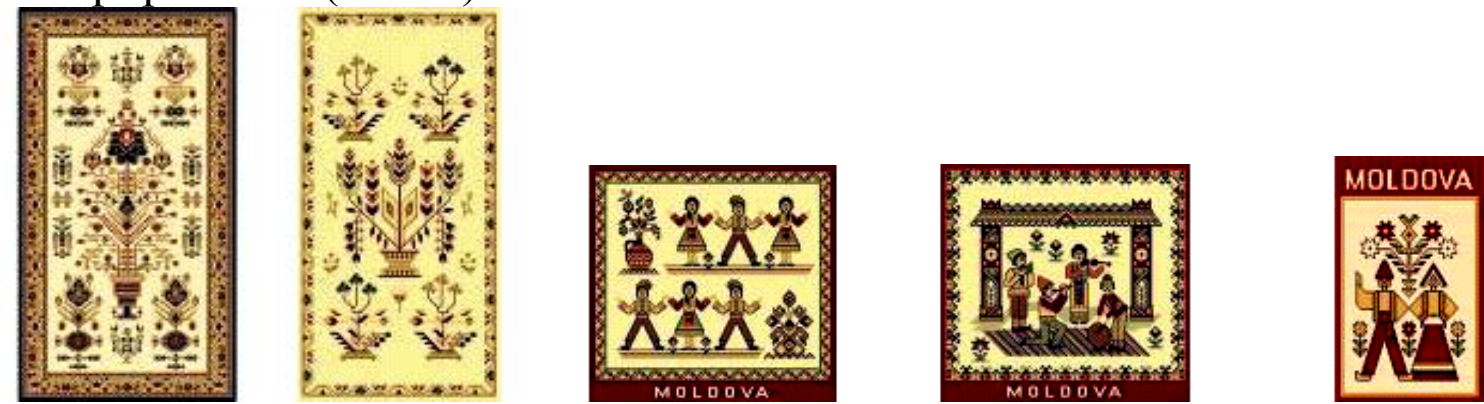

Древо жизни №192. Колосок №400. Хора №403. Дойна №404. Мэричишор - Молдова №027 (01126).

Рис. 4. Молдавские коврики-сувениры АО Флоаре-Карпет в духе народных традиций.

Четкость линий рисунка в коврах Модерн достигается благодаря ворсу средней длины и высокой плотности плетения изделия. Koвpы данного стиля с абстрактными рисунками актуальны для ультрасовременного пространства и особенно для жителей мегаполисов (Рис. 2).

К аутентичной коллекичии Этно (Etno) относятся 1.Florina №584; 2.Camelia №585; 3.Basarab №586; 4.Cozmin №588; 5.Sanziana №589; 6.Cipy №611. Для нее специально были разработаны и обогащенны традиционные колориты, близкие к народныл традициям, с оттенками насыщенного красного и других натуральных цзветов - 3236, 3632, 62336, 63632, 63236, 60364 и 60360 (Рис. 5).

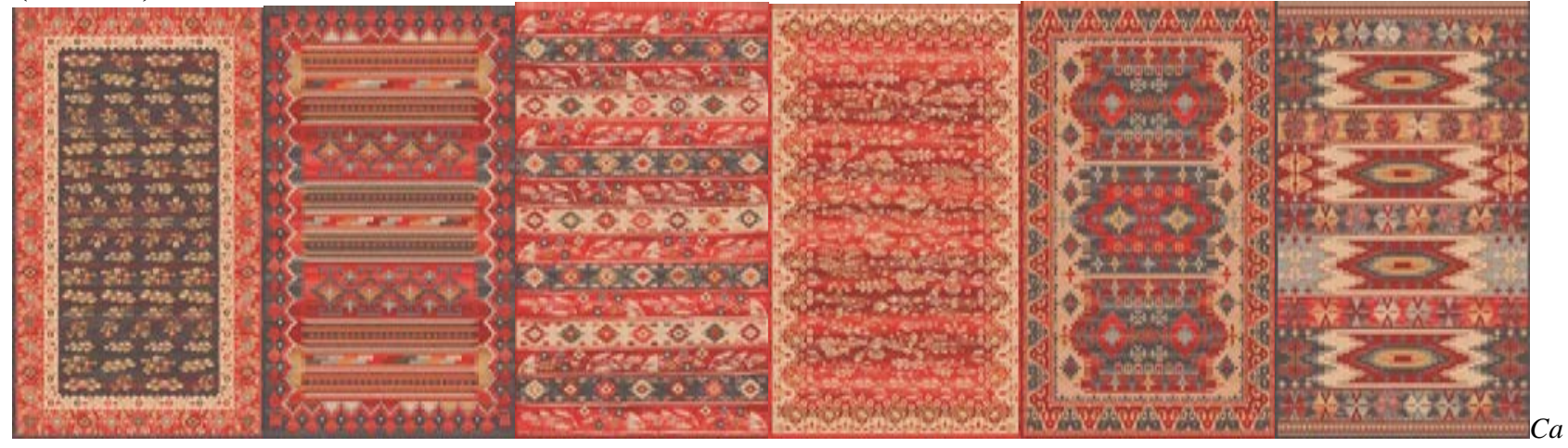

melia №585(6.3236). Cipy №611(6.3236). Florina №584(6.3632). Sanziana №589(6.3632). Cozmin №588(6.3632). Basarab №586 (6.3236).

Рис. 5. Коллекция ковров Этно в рамках фабрики АО Флоаре-Карпет в Кишиневе, 2015 (Фото: сайт предприятия) 


\section{Выводы}

Современные течения в текстильном (ковровом) искусстве в индустриальной системе Молдовы, помимо дизайна оригинальных образцов ковров, предполагают разработку совершенно иных расиветок изделий, новые поиски художников и колористов, отвечающие требованиям модернизированного общества. Это означает, что за 40-летний опыт работы мастерами предприятия АО Флоаре-Карпет был создан широкий спектр популярных колоритов, использующихся ранее в производстве и востребованных до сих пор. За всю историю фабрики насчитывается более 50 колоритов, частично представленных автором в статье. Анализ данного материала может быть полезным для студентов, аспирантов (по профилю изобразительное/декоративное искусство, дизайн), педагогов (по ИЗО и технологии), дизайнеров, искусствоведов, этнографов, культурологов - в ходе исследований научного этнопедагогического, критического и историкоэтнографического и искусствоведческого характера. Также в качестве вспомогательного компонента - помочь начинающим художникам, дизайнерам, текстильщчикам правильно подбирать и сочетать цвета в создании /проектировании своих собственных текстильных произведений с учетом канонов иветоведения и многолетнего опыта профессиональных художников Молдовы.

\section{Литература:}

1. Бабина, Ю.И., „Развитие молдавского ковра в современной индустриальной системе Республики Молдова (на примере АО «ФлоареКарпет»)", в Научные исследования, Российский научно-исследовательский журнал, 2016. № 10 (11). - с. 101-104.

2. Бабина, Ю.И., „Роль художника-дизайнера в современном промышленном

производстве ковров в Республике Молдова (на примере АО «ФлоареКарпет»)”, в International Scientific Review, 2016, № 11 (21), с. 89-93.

3. Ковры-Флоаре.Каталог.URL: http://www.kovry-floare.ru/good (дата обращения: 17.03.2019).

4. Каталог Московер. URL: http://moskover.ru/catalog/search2/all/ (дата обращения: 17.03.2019).

\section{References:}

1. Babina, Ju.I., „Razvitie moldavskogo kovra $\mathrm{v}$ sovremennoj industrial'noj sisteme Respubliki Moldova (na primere AO «Floare-Karpet»)”, v Nauchnye issledovanija, Rossijskij nauchno-issledovatel'skij zhurnal, 2016. № 10 (11). - s. 101-104.

2. Babina, Ju.I., „Rol' hudozhnika-dizajnera v sovremennom promyshlennom proizvodstve kovrov v Respublike Moldova (na primere AO «Floare-Karpet»)", v International Scientific Review, 2016, № 11 (21), s. 89-93.

3. Kovry-Floare. Katalog. URL: http://www.kovry-floare.ru/good (data obrashhenija: 17.03.2019).

4. Katalog Moskover. URL: http://moskover.ru/catalog/search2/all/ (data obrashhenija: 17.03.2019). 
Abstract. In this article, the main colors of modern floor coverings and carpets developed over a period of decades by professional artists and colorists in the development of carpet production at the Floare-Carpet textile plant in Chisinau are studied in detail. The author provides a clear classification of carpets on existing collections and a short list of favorite samples by buyers. The main characteristics of the most popular carpets of the enterprise and advice on their application (product selection) are given in the ensemble decorating the space of modern interiors. When summarizing the results of the study, recommendations were proposed.

Key words: carpets, color/colouring, modernity, design, traditions, pattern/ornament, interior, industrial system, Floare-Carpet JSC, Moldova. 